Citation: Author (2021) Title. Phytopathologia Mediterranea 60(2): 381-385. doi: 10.36253/phyto-12805

Accepted: May 12, 2021

Published: September 13, 2021

Copyright: $@ 2021$ Author. This is anopen access, peer-reviewed article published by Firenze University Press (http:// www.fupress.com/pm) and distributed under the terms of the Creative Commons Attribution License, which permits unrestricted use, distribution, and reproduction in any medium, provided the original author and source are credited.

Data Availability Statement: All relevant data are within the paper and its Supporting Information files.

Competing Interests: The Author(s) declare(s) no conflict of interest.

Editor: Josep Armengol Forti, Polytechnical University of Valencia, Spain.

\section{Research Papers \\ Adult plant resistance to white rust in Lunaria annua}

\author{
Diana CERVANTES ${ }^{1}$, Mary RIDOUT ${ }^{1}$, Claudia NiSCHWITZ ${ }^{2}$, George \\ NEWCOMBE ${ }^{1, *}$ \\ ${ }^{1}$ College of Natural Resources, University of Idaho, Moscow ID, USA \\ ${ }^{2}$ Department of Biology, Utah State University, Logan, UT 84322, USA \\ ${ }^{*}$ Corresponding author. E-mail: georgen@uidaho.edu
}

Summary. Wild plants produce abundant seeds and seedlings, but most die before reaching maturity, and these premature deaths are often caused by pathogens. Major genes for resistance protect some seedlings or juveniles. These selected individuals can become a resistant, mature cohort. Alternatively, plants can exhibit mature, adult plant resistance. These two explanations can be indistinguishable in the field, when epidemics in natural pathosystems occur regularly resulting in annual selection for resistance. This study included multi-year observations of a biennial plant where the distinction could be made. White rust of Lunaria annua, a pathosystem native to the Mediterranean Basin, took time in its introduced range in Idaho, USA, to generate epidemics. After years of minimal white rust, an epidemic occurred in 2017 in which first-year, juvenile plants had 20 times the sorus density of second-year, adult plants. Since white rust incidence had been minimal for years prior to 2017, the greater resistance of 2017 adults over 2017 juveniles may have been due to adult-plant resistance. This could also be due to phenology: adult plants have mature leaves, and are flowering and maturing seed, by the time that white rust begins to build up on leaves of juveniles. The juvenile-adult difference was maintained in 2018. In white blister rusts, interpretation of resistance can also be complicated by the frequency of asymptomatic infections that adult plants would pass on to the next generation. However, we found no asymptomatic infection of seeds of $L$. annua in our sampling of the Idaho population.

Key words. Plant defense, biotrophic parasite, Brassicaceae, Albugo.

\title{
INTRODUCTION
}

Plants in nature vary in life history, and some pathogens only affect early or late stages of the life history of their host plants (Agrios, 1997). For example, damping-off pathogens attack seedlings of many plants, but wood decay fungi only affect later stages of woody plants that may by then be many years of age. Resistance to certain pathogens changes with the age of their host plants. This is frequently called 'age-related resistance' (Panter and Jones, 2002), although 'mature plant resistance' and 'adult plant resistance' are also terms that are sometimes employed. Adult plant resistance has been inten- 
sively studied in crop hosts (e.g., wheat, maize, tomato, Brassica spp. - Nazareno and Roelfs, 1981; Stewart et al, 1983; Bansal et al, 1999; Lin and Chen, 2007) and also in model plants such as Arabidopsis and tobacco (Panter and Jones, 2002; Develey-Rivière and Galiana, 2007). Biennial plants are likely to be good hosts for study of adult plant resistance in this way. First-year plants are juveniles, and second-year plants are mature, having flowered and set seed for the first and only time.

Lunaria annua (money plant) is a biennial native to the Mediterranean Basin, that is introduced and somewhat weedy in North America (Newcombe et al, 2009). Many of the fungus and oomycete pathogens of L. annua have only been reported from western Europe (Farr and Rossman, 2018), where the plant is an archaeophyte. White rusts are economically important pathogens (Saharan and Verma, 1992), and the host range of Albugo candida is well known (Choi et al, 2009). The probable first specimen of white rust, or 'white blister rust', of money plant, caused by Albugo candida, was collected in England in 1960 (BPI 184980). This disease was not reported in North America until 2004. in Washington State (Glawe et al., 2004), and was collected in Oregon in 2000 and deposited in CUP as CUP-065639. Subsequently, the disease was found in the neighboring state of Idaho (Newcombe et al., 2009). The present authors have made annual observations since 2000 of this reconstituted pathosystem (i.e., it is reconstituted in that both host and pathogen are native elsewhere).

Annual observations have been made in the Shattuck Arboretum of the University of Idaho. Lunaria annua is a common understory plant in the 'Old Arboretum', with thousands of individuals representing each of the two age cohorts. White rust was at very low incidence and severity at the time of its discovery (Newcombe et al., 2009), and observations have been made annually since then.

In 2017 an epidemic of white rust developed on L. annua. The disease became obvious by early summer and juvenile plants were much more diseased than adult plants. This epidemic was seen as an opportunity to gain insights, using observational methods, into adult-plant resistance in a biennial, non-crop plant. In particular, this allowed possible distinction between selection in the juvenile phase and expression of adultplant resistance. Adult-plant resistance to white rust has been noted in Arabidopsis thaliana (Holub, 2008), and in many other pathosystems, where different names for this phenomenon have been used (e.g., ontogenic, developmental, or age-related resistance; Develey-Rivière and Galiana, 2007).

\section{MATERIALS AND METHODS}

Observations on white rust of Lunaria annua from 2009 to 2016

Incidence and severity of white rust were recorded each year from 2009 to 2016, in early summer each year, on paths through the 'Old Arboretum', where a robust population of thousands of L. annua plants has been present for several decades. Each year, incidence was determined as the percentage of 500 plants ( 250 juveniles and 250 adults) with any white rust on any of their leaves. Severity was determined as the number of white rust sori on the worst affected leaf of each affected plant.

Severity of white rust during the epidemic years of 2017 and 2018

Intermixed juvenile and adult plants were scored for while rust severity throughout the 'Old Arboretum' during the epidemic in early July of 2017 and 2018. A $1 \mathrm{~m}^{2}$ quadrant was used to designate 26 representative quadrants containing totals of 194 adult and 348 juvenile plants. Sori were counted on each plant on the second set of leaves from the bottom (i.e., the third and fourth oldest leaves), that were typically the most severely affected by white rust. Each sorus was counted, occasionally using a dissecting microscope to differentiate between closely clustered sori. These data consisted of counts of individual $A$. candida sori on the undersides of the second sets of leaves of 542 plants in 2017 and 100 in 2018. This measure of incidence was conservative, in that plants with no sori on the second set of leaves sometimes had rust sori on other leaves.

Molecular testing for Albugo candida in seeds of infected plants

Seeds from 25 plants with some leaf white rust infections were collected and tested for the presence of Albugo candida. Ten seeds from each of 13 plants were combined for testing (No. $=13)$. Ten seeds of each of 12 plants were tested individually $($ No. $=120)$. DNA was extracted using the Qiagen DNeasy Plant Mini kit following the manufacturer's protocol. Twenty-five microliter PCR reactions were set up using Accuprime Pfx Supermix and a two-step PCR was carried out using oomycete- and Albugo-specific primers and conditions described by Ploch and Thines (2011). The resulting PCR products were visualized in a $1 \%$ agarose gel stained with ethidium bromide. 


\section{Statistical analyses}

The Shapiro-Wilk and the Anderson-Darling tests were used to evaluate normality of the data collected. The data were then analyzed using the nonparametric Kruskal-Wallis test to determine difference in disease severity between the juvenile and adult individuals of $L$. annua.

\section{RESULTS}

Observations on white rust of Lunaria annua from 2009 to 2016

Annual surveys from 2009 to 2016 inclusive, of the 500 plant samples from the population of thousands of L. annua plants in the 'Old Arboretum', revealed low white rust incidence. Each year only one to five plants were found with white rust. Severity was also low with from one to four sori on the worst affected leaves, that were typically the third or fourth oldest on each affected plant. In 2016, the last year preceding the 2017 epidemic, incidence was negligible, with three white-rusted plants with, respectively, two, four and four sori per most affected leaf.

Severity of white rust during the epidemic years of 2017 and 2018

During the epidemic of 2017, 71\% of 542 surveyed plants had some white rust on the two surveyed leaves per plant. According to this conservative measure of incidence, $90 \%$ of 348 juvenile plants, and $36 \%$ of 194 second-year, adult plants were diseased. This was a highly significant difference between the juvenile and adult cohorts $\left(\chi^{2}=79.276, P<0.0001\right)$. Average numbers of sori, as a measure of disease severity, were more than 20 times greater on juvenile than in adult plants (Figure 1a). This difference was also highly significant $\left(\chi^{2}=230.927, P<0.0001\right)$. Numbers of sori on adult plants averaged $4.2 \%$ of numbers on juvenile plants. Only $1 \%$ of adult plants had 30 or more sori compared to the $49.1 \%$ of juveniles with this white rust severity (Figure 2a). Therefore, the second-year, adult plants had much less white rust than first-year juveniles during the 2017 epidemic, and this difference was obvious from visual observations.

During the epidemic of $2018,83 \%$ of the 100 surveyed plants had some white rust on the two surveyed leaves per plant. According to this conservative measure of incidence, $96 \%$ of 50 juvenile plants, and $70 \%$ of
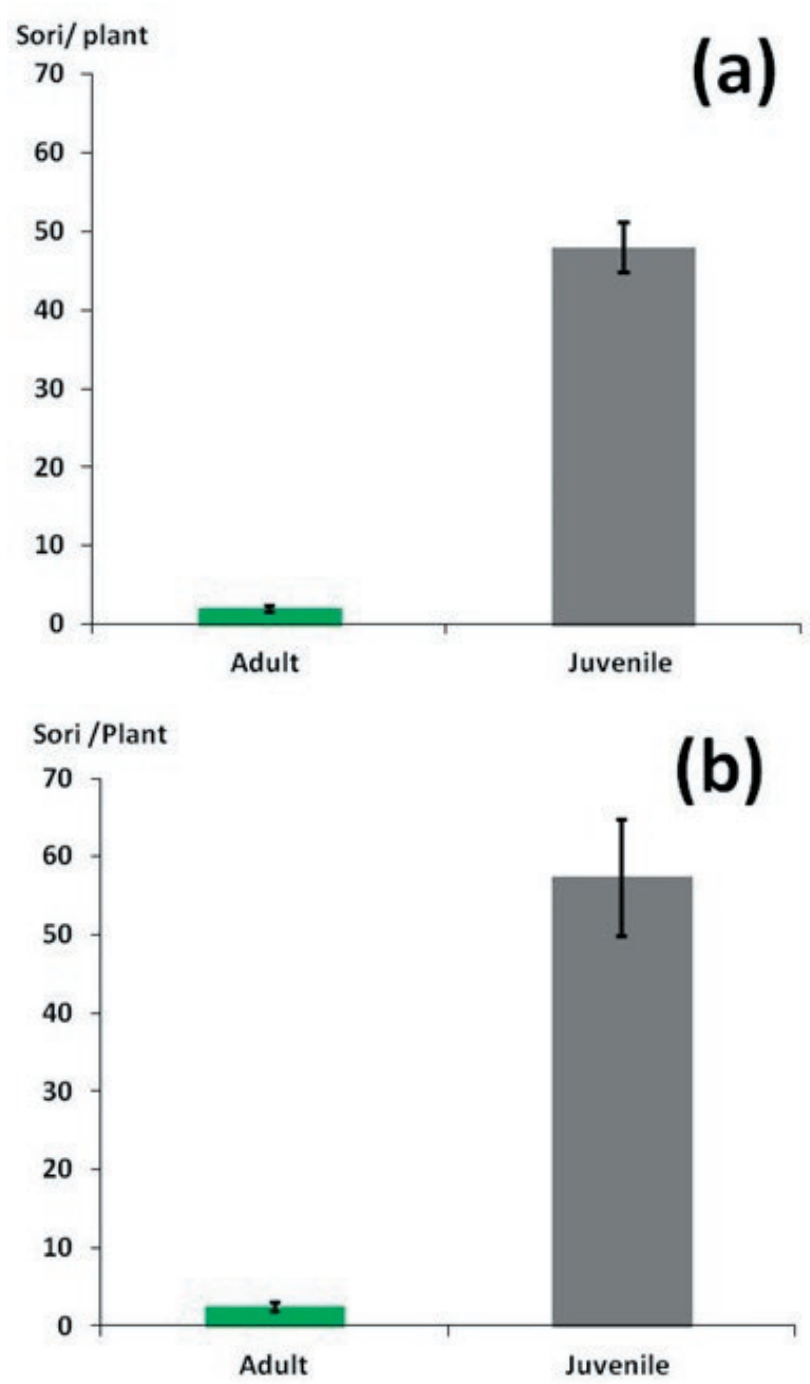

Figure 1. (a) Average numbers of Albugo candida sori per plant on Lunaria annua plants in 2017. (b) Average numbers of A. candida sori per plant on L. annua plants in 2018.

50 second-year, adult plants were diseased. This was a highly significant difference between the juvenile and adult cohorts $\left(\chi^{2}=7.1241, P=0.0076\right)$. Numbers of sori on leaves of juvenile plants were more than 23 times greater than those on leaves of adult plants (Figure $1 b)$. This difference was highly significant $\left(\chi^{2}=58.205\right.$, $P<0.0001)$. Numbers of sori on adult plants averaged $0.043 \%$ of those on juvenile plants. Only $2 \%$ of the adult plants had 30 or more sori compared to the $80 \%$ of juveniles with this severity (Figure $2 \mathrm{~b}$ ). Therefore, the second-year, adult plants had much less white rust than first-year juveniles, and this difference was visually obvious. 

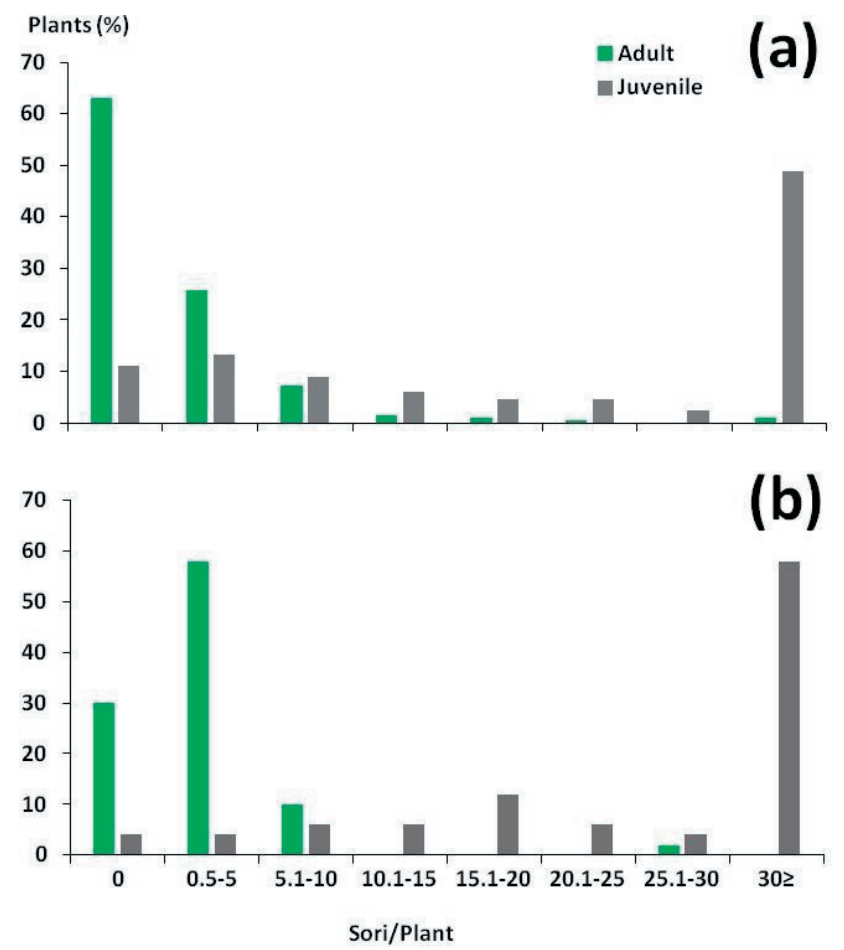

Figure 2. Distributions of average numbers of Albugo candida sori on Lunaria annua plants, in (a) 2017 and (b) 2018.

Molecular testing for Albugo candida in seeds of infected plants

Any PCR products close to the expected size for the Albugo-specific primers were sequenced. The sequences were very variable, and were probably randomly attached to the host genome at multiple sites. No Albu$g o$ was detected in any seeds of leaf-infected $L$. annua. To confirm that no Albugo was present, primers ITS 4 and ITS 5 (White et al., 1990) were used on the DNA extracted from seeds. Only part of the ITS region of L. annua was amplified. Sequences of Albugo or other microorganisms were not detected.

\section{DISCUSSION}

This study has detected greater incidence and severity of white rust in juvenile $L$. annua plants than in adult plants. The study considered the possibility that greater resistance of adult plants could be due either to prior selection for resistance or to persistent, systemic infections. However, the observations and data did not support these hypotheses. Instead, they indicated that there were differing phenologies for juvenile and adult plants.
Plants in this study were naturally interspersed. However, without controlled inoculations, inferences about juvenile and adult plant resistance face different challenges. Firstly, there is the problem of prior selection. 2017 was the first year of a severe white rust epidemic, so the detection of stronger adult plant than juvenile resistance in that year was supported. Prior selection was unlikely given the much lower levels of white rust in the preceding years.

A second challenge was the possibility of persistent systemic infections, since simple counts of pustules would then have been an inaccurate measure of infection. Systemic infection has been reported for Albugo candida in some species of Brassicaceae, including Lepidium campestre, Erysimum menziesii subsp. eurekense, and Arabis lyrata (Jacobson et al., 1998). Systemic infections frequently, but not always, result in sterile, distorted host inflorescences that are commonly described as 'stagheads'. In Brassica napus, stagheads are associated with greatly reduced seed yields (Harper and Pittman, 1974; Petrie, 1988). Stagheads in L. annua were not observed in the UI Arboretum. Assessments for presence of A. candida in bulked and individual seeds of 25 plants showed no evidence of systemic infections, and no reports of systemic white rust infections in L. annua have been found in the literature. The absence of systemic infection may in part be a function of the host responses, but there are also likely to be differences related to host specificity that were at first thought to be at the 'strain' level in A. candida (Sansome and Sansome, 1974).

Another possible explanation for the present results could be the difference in phenology of juvenile and adult L. annua plants. Adult plants flower in the UI Arboretum before juvenile plants begin to become infected by A. candida. By early July, adult plants have finished flowering and their seeds are maturing. Juvenile plants, in contrast, possess only relatively young and susceptible leaves in late June and early July.

Differences in resistance between juvenile and adult of species of Brassicaceae have been previously reported. Adult plants usually showed greater resistance to white rust than juvenile seedlings in a study involving growthchamber inoculations of Lepidium campestre, Erysimum menziesii subsp. eurekense, and Arabis lyrata (Jacobson et al., 1998). This was true even for new leaves of adult plants, in that they were less susceptible than new leaves of young seedlings in the three species examined by Jacobson et al. (1998).

The present study has demonstrated adult plant resistance in $L$. annua to white rust, and this allows speculation on the theory of optimal host defense for this pathosystem. This theory proposes that at the level 
of an individual host plant, defense is weakest when tissues are most expendable, and is strongest when tissues are most valuable. Vegetative tissues are considered to be more expendable, and reproductive tissues more valuable, for overall plant fitness. This distinction has been demonstrated in another species of Brassicaceae, Boechera stricta (Keith and Mitchell-Olds, 2017), in which defense-related glucosinolates were more concentrated in reproductive than in vegetative tissues. But this idea might be difficult to disentangle from the phenological differences between juveniles and adults.

\section{LITERATURE CITED}

Agrios G.N., 1997. Plant Pathology, Fourth Edition. Academic Press. CA.

Bansal V.K., Thiagarajah M.R., Stringam G.R., Tewari J.P., 1999. Inheritance of partial resistance to race 2 of Albugo candida in canola-quality mustard (Brassica juncea) and its role in resistance breeding. Plant Pathology 48(6): 817-822.

Choi Y.J., Shin H.D., Thines M., 2009. The host range of Albugo candida extends from Brassicaceae through Cleomaceae to Capparaceae. Mycological Progress 8(4): 329.

Develey R.M.P., Galiana E., 2007. Resistance to pathogens and host developmental stage: a multifaceted relationship within the plant kingdom. New Phytologist 175(3): 405-416.

Farr D.F., Rossman A.Y., Fungal Databases: U.S. National Fungus Collections. Available at: https://nt.ars-grin. gov/fungaldatabases/. Accessed October 29, 2018.

Glawe D.A., Glass J.R., Putnam M.L., 2004. First report of white rust of Lunaria annua caused by Albugo candida in North America. Plant health progress: 1-2.

Harper F.R., Pittman U.J., 1974. Yield loss by Brassica campestris and $B$. napus from systemic infection by Albugo cruciferarum. Phytopathology 64: 408-410.

Holub E.B., Springer D., 2008. Natural history of Arabidopsis thaliana and oomycete symbioses in the downy mildews-genetics. Molecular Biology and Control: 91-109.

Jacobson D.J., LeFebvre S.M., Ojerio R.S., Berwald N., Heikkinen E., 1998. Persistent, systemic, asymptomatic infections of Albugo candida, an oomycete parasite, detected in three wild crucifer species. Canadian Journal of Botany 76(5): 739-750.

Keith R.A., Mitchell O.T., 2017. Testing the optimal defense hypothesis in nature: variation for glucosinolate profiles within plants. PloS one 12(7): 0180971.
Nazareno N.R.X., Roelfs A.P., 1981. Adult plant resistance of Thatcher wheat to stem rust. Phytopathology 71: 181-185.

Newcombe G., Gaylord R., Yenish J.P., Mastrogiuseppe J., Dugan F.M., 2009. New records for pathogenic fungi on weedy or non-indigenous plants. North American Fungi 4: 1-12.

Panter S.N., Jones D.A., 2002. Age-related resistance to plant pathogens. Advances in Botanical Research 38: 252-281.

Petrie G.A., 1988. Races of Albugo candida (white rust and staghead) on cultivated Cruciferae in Saskatchewan Canadian Journal of Plant Pathology 10: 142150.

Ploch S., Thines M., 2011. Obligate biotrophic pathogens of the genus Albugo are widespread as asymptomatic endophytes in natural populations of Brassicaceae. Molecular Ecology 20: 3692-3699.

Saharan G.S., Verma P.R., 1992. White rusts: a review of economically important species. International Development Research Centre.

Sansome E., Sansome F.W., 1974. Cytology and life-history of Peronospora parasitica on Capsella bursa-pastoris and of Albugo candida on C. bursa-pastoris and on Lunaria annua. Transactions of the British Mycological Society 62(2): 323-IN24.

Stewart H.E., Taylor K., Wastie R.L.,1983. Resistance to late blight in foliage (Phytophthora infestans) of potatoes assessed as true seedlings and as adult plants in the glasshouse. Potato Research 26(4): 363-366.

White T.J., Bruns T., Lee S., Taylor J., 1990. PCR Protocols: A guide to methods and applications. Academic Press Inc., San Diego, California, USA. 